\title{
O ensino da dança na escola na ótica dos professores de Educação Física e de Arte
}

CDD. 20.ed. 796.017

http://dx.doi.org/10.1590/1807-55092014000300505
Nilza Coqueiro Pires de SOUSA* Dagmar Aparecida Cynthia França HUNGER ${ }^{* *}$ Sandro CARAMASCHI ${ }^{* *}$
*Instituto de Biociências, Universidade Estadual Paulista - Rio Claro.

**Faculdade de Ciências, Universidade Estadual Paulista - Bauru.

\section{Resumo}

0 objetivo deste estudo descritivo, de natureza qualitativa e quantitativa, foi analisar se o conteúdo referente à dança está discriminado no Projeto Político Pedagógico (PPP) das Escolas; como se apresenta o ensino da dança nas aulas de Educação Física e de Arte; qual o conhecimento dos professores do conteúdo dança preconizado nos Parâmetros Curriculares Nacionais (PCN's); qual importância é dada ao ensino da dança na escola e quais são os seus limites. Utilizou-se um questionário com questões abertas e fechadas para 64 professores efetivos de Educação Física e de Arte da rede pública estadual e municipal de uma cidade do interior do Estado de São Paulo. Em síntese, constatou-se que esses professores não têm uma participação efetiva e coletiva durante o processo de construção do PPP educacional; que eles conhecem, mas aplicam muito pouco e com restrições os conteúdos de dança sugeridos pelos PCN's; que estão relegadas basicamente às festividades escolares e que são muitas as dificuldades enfrentadas pelos professores no ensino da dança na escola. Conclui-se como necessária à união e integração desses educadores em prol do ensino da dança na escola, para que ela ocupe efetivamente seu espaço nas aulas de Educação Física e de Arte.

PalavRas-chave: Dança; Projeto político pedagógico; Parâmetros curriculares nacionais; Educação física; Arte.

\section{Introdução}

Atualmente o panorama da dança no contexto escolar é desenvolvido tanto pela área da Educação Física quanto pela Arte, sendo o processo de ensino e aprendizagem diferenciado, principalmente diante de diversas articulaçóes teóricas (filosóficas, científicas e pedagógicas) por que tem passado essas disciplinas. Observamos que a dança ainda passa por um processo de valorização, já que nem sempre consegue o devido espaço comparando-se com os demais conteúdos escolares ${ }^{1}$.

A dança considerada historicamente a mais antiga das manifestaçóes socioculturais, sempre esteve pouco presente nas escolas, apesar do ensino de Educação Física e de Arte alcançar cada vez mais espaço no âmbito escolar. Morandi ${ }^{2}$ enfatiza que a dança além de se deparar com problemas (formação inicial, predominância dos esportes e das artes visuais, falta de diversificaçáo de conteúdos, falta de aprofundamento, etc.) metodológicos e conceituais, ainda não conseguiu proporcionar equivalência de enfoque nas diversas possibilidades dos conteúdos dessas duas áreas.

Os PCN's foram elaborados há 17 anos e, hoje, é passível de críticas com referência a sua construção, conteúdos e referenciais teóricos ${ }^{3}$. No entanto, ainda são utilizados pelos professores no planejamento, pois na rede estadual para os anos iniciais do ensino fundamental apenas existe na atualidade uma versão preliminar das expectativas de aprendizagem para as disciplinas de Arte ${ }^{4-5}$ e Educação Física ${ }^{5}$ com um roteiro de sugestóes de atividades, a qual está em processo inicial de implantação. Já a rede municipal de Bauru/ $\mathrm{SP}^{6}$ finalizou o seu currículo comum para o ensino fundamental recentemente, em que a equipe escolar está em fase de discussóes e reflexôes para a elaboração do seu PPP. Nesse sentido, na presente pesquisa optou-se pelos PCN's, dado o fato desse material ser o referencial, majoritariamente, mais utilizado e conhecido pelos professores. 
O ensino da dança nas escolas públicas brasileiras deve ser abordado dentro dos conteúdos de Educação Física (Jogos, Ginástica, Lutas, Dança e Atividades Rítmicas) e também de Arte (Teatro, Música, Dança e Artes Plásticas) segundo os PCN's, documento que fornece subsídios para o trabalho dos conteúdos programáticos na escola. Neste documento, a Educação Física não exclui o conteúdo dança de seu campo de atuação e afirma que o ensino de dança na escola deve ser de responsabilidade tanto do professor de Arte ${ }^{7}$ quanto do professor de Educação Física ${ }^{8}$.

Ao considerarmos que a inserção da dança no âmbito educacional poderia ser mais efetiva caso estivesse inserido no PPP da escola, entendemos que este documento é o plano global da instituição. Por isso, ao construí-lo coletivamente durante o planejamento escolar, toda a equipe gestora (direção, coordenação, professores, pais, alunos, etc) discutirá, refletirá e decidirá as formas de organização escolar pedagógica.

Para a construção do PPP da escola, VEIGA ${ }^{9}$ apresenta sete elementos básicos (finalidades, estrutura organizacional, currículo, tempo escolar, processo de decisão, relaçôes de trabalho e avaliação) para gestar uma nova organização de trabalho pedagógico.

Partindo do pressuposto que no currículo estáo inseridos os conteúdos, metodologias e procedimentos selecionados durante o planejamento, acreditamos que se os conteúdos de dança estiverem contemplados neste documento, aumentam as possibilidades do ensino da dança acontecer nas escolas de maneira sistemática, privilegiando o processo de ensino e aprendizagem, bem como, a interdisciplinaridade entre ás áreas do conhecimento.

Diante de toda a problemática envolvendo as dificuldades enfrentadas pelos professores de Arte e de Educação Física em relação aos conteúdos da dança na escola, objetivou-se analisar se os conteúdos referentes à dança estáo discriminados no PPP das escolas; como se apresenta o ensino da dança nas aulas de Arte e de Educação Física; qual o conhecimento dos professores a respeito dos conteúdos de dança preconizado nos PCN's; qual importância é dada ao ensino da dança na escola e quais sáo os limites desse ensino da dança na escola.

Partindo dessa perspectiva, nosso estudo inicia com a pesquisa bibliográfica da produçáo teórica referente ao PPP, mais especificamente no que se refere ao currículo e tempo escolar apresentado por VeIGA'; ao ensino da dança na escola, elencando pontos (reconhecimento da importância da dança na educação, bem como, os objetivos, as finalidades, os conteúdos e os procedimentos do ensino da dança) importantes para refletirmos sobre qual dança queremos na escola, os quais são apresentados por vários pesquisadores ${ }^{2,10-14}$ dessas áreas. Apresentamos ainda as aproximaçóes e os distanciamentos entre os PCN's de Arte e de Educação Física no que tange a compreensão da dança no currículo.

\section{Projeto político pedagógico}

Segundo Betini ${ }^{15}$ o PPP mostra a visão macro do que a instituição escola pretende ou idealiza fazer, seus objetivos, metas e estratégias permanentes, tanto no que se refere às suas atividades pedagógicas, como às funçôes administrativas. Portanto, essa autora ressalta que o PPP faz parte do planejamento e da gestáo escolar.

A questão principal do planejamento é expressar a capacidade de se transferir o planejado para a ação. Assim sendo, compete ao PPP à operacionalização do planejamento escolar, em um movimento constante de reflexão-ação-reflexão ${ }^{16}$.

Por isso, consideramos o planejamento escolar um aspecto importante para a construção do PPP. Neste artigo pretendemos analisar o desenvolvimento de conhecimentos específicos e particulares de uma disciplina, no caso específico do nosso estudo, ensino da dança, por estar inserida em duas disciplinas como a Arte e a Educação Física.

VeIgA ${ }^{9}$ enfatiza que a importância do PPP está no fato de que ele passa a ser uma direção, um rumo para as açōes da escola. É uma ação intencional que deve ser definida coletivamente, com consequente compromisso coletivo. É político porque reflete as opções e escolhas de caminhos e prioridades com a formação do cidadão e é pedagógico porque expressa as açóes educativas e didáticas que levam a escola a alcançar os seus objetivos educacionais e sua intencionalidade.

Desta forma, a dimensão política se cumpre na medida em que ela se realiza enquanto prática especificamente pedagógica. A construção do PPP é de fundamental importância, pois ele é a concretização da identidade da escola e do oferecimento de garantias para um ensino de qualidade?

Desse modo, o PPP tem a ver com a organização do trabalho pedagógico em dois níveis: como organizaçấo da escola com um todo e como organização da sala de aula, incluindo sua relação com o contexto social imediato, procurando preservar a visão de totalidade? . 
O PPP no estudo de VEIGA 9 é entendido como a própria organização do trabalho pedagógico da escola, que parte dos princípios de igualdade, qualidade, liberdade, gestão democrática e valorização do magistério. A autora descreve que podem ser apontados pelo menos sete elementos básicos para a construção de um PPP como as finalidades da escola, a estrutura organizacional, o currículo, o tempo escolar, o processo de decisão, as relaçôes de trabalho e a avaliação.

Não é intenção deste trabalho, nesse momento, realizar um estudo abrangente dos sete elementos básicos para a construção do PPP, mas enfatizamos que todos esses pressupostos são importantes. Contudo, abordaremos neste tópico os elementos básicos a respeito do currículo e do tempo escolar, com base nos resultados encontrados neste artigo com o intuito de embasar a nossa discussão.

No que se refere ao currículo, VEIGA ${ }^{9}$ enfatiza que este é um importante elemento constitutivo da organização escolar, que implica, necessariamente, a interação entre sujeitos que têm um mesmo objetivo e a opção por um referencial teórico que o sustente. A autora menciona ainda que

o currículo é uma construção social do conhecimento, pressupondo a sistematização dos meios para que esta construção se efetive; a transmissão dos conhecimentos historicamente produzidos e as formas de assimilá-los, portanto, produção, transmissão e assimilação são processos que compõem uma metodologia de construção coletiva do conhecimento escolar, ou seja, o currículo propriamente dito. Neste sentido, o currículo refere-se à organização do conhecimento escolar (p.26-7).

O tempo escolar segundo VEIGA ${ }^{9}$ é a organização do tempo do conhecimento escolar. A autora ressalta que

o calendário escolar ordena o tempo: determina o início e o fim do ano, prevendo os dias letivos, as férias, os períodos escolares, etc. O horário escolar, que fixa o número de horas por semana e que varia em razão das disciplinas constantes na grade curricular, estipula também o número de aulas por professor. É preciso tempo para que os educadores aprofundem seu conhecimento sobre os alunos e sobre o que estão aprendendo. É preciso tempo para acompanhar e avaliar o PPP em ação. É preciso tempo para os estudantes se organizarem e criarem seus espaços para além da sala de aula (p.29).

Diante do exposto, VEIGA ${ }^{9}$ ressalta que é preciso entender o PPP da escola como uma reflexão de seu cotidiano. Para tanto, ela precisa de um tempo razoável de reflexão e ação, para se ter um mínimo necessário à consolidação de sua proposta. Dessa maneira, a construção do PPP requer continuidade das açóes, descentralização, democratização do processo de tomada de decisóes e instalação de um processo coletivo de avaliação de cunho emancipatório.

O que fica claro é que o PPP da escola, quando bem construído e administrado, pode ajudar alcançar os seus objetivos de forma decisiva. A sua ausência, por outro lado, pode significar um descaso com a escola, com os alunos, com a educação em geral, o que, certamente, refletirá no desenvolvimento da sociedade em que a escola estiver inserida ${ }^{15}$.

\section{O ensino da dança na escola}

De acordo com Morandi ${ }^{2}$, o processo de reconhecimento da importância da dança na educação é recente (década de 90). Atrelada a diferentes campos de conhecimento, como a Arte e Educação Física, carregam consigo ainda vestígios e preceitos negativos que historicamente (primeira metade do século XX) impediram sua inserção nas escolas como uma área de conhecimento específica e autônoma.

O professor de Arte e de Educação Física se depara com uma possibilidade enorme de conteúdos de dança que podem ser trabalhados na escola, porém muitas vezes náo sabe por que, para que, o que e como dançar ${ }^{10-13}$. De acordo com esses autores, sem uma reflexão sobre o ensino da dança, ela se torna uma ação desprovida de propósitos, uma educação vazia de sentido, significados e objetivos.

Segundo Scarpato ${ }^{14}$ a dança na escola não deve priorizar a execução de movimentos corretos e perfeitos dentro de um padrão técnico imposto, gerando a competitividade entre os alunos. Deve partir do pressuposto de que o movimento é uma forma de expressão e comunicação do aluno, objetivando torná-lo um cidadão crítico, participativo e responsável, capaz de expressar-se em variadas linguagens, desenvolvendo a auto-expressão e aprendendo a pensar em termos de movimento.

Outro aporte teórico adotado nessa pesquisa se refere aos $\mathrm{PCN}^{7-8}$, pois é um material didático que serve como parâmetro para as redes de ensino estadual e municipal, visando auxiliar o planejamento e desenvolvimento dos conteúdos de dança das respectivas disciplinas e ainda é acessível para os professores no próprio "lócus" de atuação. Apresentaremos a seguir as aproximaçóes e distanciamentos do ensino da dança de acordo com os PCN's de Arte e Educação Física para os Anos Iniciais do Ensino Fundamental. 


\section{Aproximações e distanciamentos entre o ensino da dança nos PCN's de Arte e Educação Física}

O ensino da dança na escola aparece nas disciplinas de Arte e Educação física e deveria ser abordada de forma mais ampla e significativa ${ }^{2}$. Uma das aproximaçôes existentes entre as áreas de Arte e Educação Física se refere à utilizaçáo e movimentaçáo do corpo ${ }^{17-18}$, isto significa, que tanto uma quanto a outra área "utilizam a expressão corporal como linguagem"19. Nesta direção, PACHECO ${ }^{11}$ aponta que ambas as áreas apresentam características comuns como o estudo no âmbito motor, além de aspectos artísticos e culturais.

Diante do exposto, abordaremos o ensino da dança de acordo com a proposta preconizada pelos PCN's de Arte e Educaçáo Física, procurando compreender as aproximaçóes e distanciamentos existentes no currículo dessas duas áreas de conhecimento.

De acordo com os PCN's de Arte, o ensino da dança tem como propósito o desenvolvimento integrado do aluno, em que a experiência motora permita observar e analisar as açóes humanas propiciando o desenvolvimento expressivo. Dentre os objetivos gerais sob o enfoque da Arte destacam-se às experiências dos movimentos corporais dos alunos, na qual possibilite ao aluno a capacidade de construir uma relação de cooperação, situar e compreender as relaçôes entre corpo, dança e sociedade. Dessa maneira, os direcionamentos pretendem estimular os alunos a produzir, compreender e analisar os próprios trabalhos e apreender noçóes e habilidades para a apreciação estética e análise crítica do patrimônio cultural artístico.

Enquanto os PCN's de Educação Física entendem que, por meio das danças e brincadeiras os alunos poderão conhecer as qualidades do movimento expressivo, além de algumas técnicas de execução de movimentos, bem como, ser capazes de improvisar, de construir coreografias, e, por fim, de adotar atitudes de valorização e apreciação dessas manifestaçóes expressivas.

O conjunto de conteúdos da dança nos PCN's de Arte está articulado dentro do contexto de ensino e aprendizagem em três eixos norteadores: a produção (fazer artístico), a fruição (apreciaçáo) e a reflexáo (compreensão), na qual se articulam na prática, ao mesmo tempo em que mantêm seus espaços próprios. Os conteúdos poderão ser trabalhados em qualquer ordem, segundo decisão do professor, em conformidade com o desenho curricular de sua equipe ${ }^{7}$.

Já os PCN's de Educação Física abordam os conteúdos de atividades rítmicas e expressivas nas primeiras quatro séries, no qual estão organizados em blocos inter-relacionados (conhecimento sobre o corpo e esportes, jogos, lutas e ginásticas), explicitando como possíveis enfoques da ação do professor e não como atividades isoladas.

No que tange aos conteúdos específicos sobre a dança, apesar dos PCN's de Arte e Educação Física não explicitarem no texto, observamos que as sugestóes de conteúdos relacionam-se com a proposta de Dança Educativa preconizada por LABAN ${ }^{20-21}$, quando indicam a conscientização e percepção corporal; os fatores de movimento espaço, tempo, peso e fluência; as qualidades expressivas e gestuais do movimento; o relacionamento do aluno consigo mesmo, com os outros e com o mundo e ainda, com as atividades de improvisação e os processos criativos de sequência de movimento e ou coreografias a serem realizadas individualmente, em duplas, grupos e coletivamente.

Outros pontos de aproximação entre os PCN's de Arte e Educação Física se refere à contextualização dos conteúdos da dança, ou seja, o conhecimento dos elementos históricos, culturais e sociais devido à diversidade cultural regional, nacional e internacional. Nos PCN's dessas áreas também observamos o caráter lúdico das atividades ao mencionar as brincadeiras de roda, os jogos populares, as cirandas, amarelinhas como importantes fontes de pesquisa e desenvolvimento para atividades rítmicas.

Em relação ao distanciamento entre esses documentos, evidencia-se que os PCN's de Arte fazem uma apresentação mais detalhada das sugestôes de trabalho com a dança na escola, na qual elencam três aspectos para o ensino e aprendizagem dos alunos: a dança na expressão e na comunicaçáo humana; a dança como manifestação coletiva e a dança como produto cultural e apreciação estética ${ }^{7}$. Entretanto, verifica-se que o entendimento do primeiro aspecto pode se relacionar com a intenção de expressão e comunicação mediante gestos sugeridos no bloco de conteúdos referentes a Atividades Rítmicas e Expressivas $^{8}$ e o segundo se equivale às manifestaçôes da cultura corporal. Só o terceiro aspecto seria exclusivo da disciplina de Arte.

Já os PCN's de Educação Física apresentam uma lista de sugestôes de danças e atividades rítmicas e ou expressivas que podem ser abordadas e deverão ser adaptadas a cada contexto como as danças brasileiras; as danças urbanas; as danças eruditas; as danças e coreografias associadas a manifestaçôes musicais; as lengalengas; as brincadeiras de roda, cirandas e escravos-de-jó. Além disso, menciona que o enfoque priorizado neste documento é complementar ao 
utilizado pelo bloco de conteúdo "Dança”, que faz parte do documento de Arte, no qual o professor encontrará mais subsídios para desenvolver um trabalho de dança, no que tange aos aspectos criativos e à concepção da dança como linguagem $\operatorname{artística~}^{7}$ (p.51).

\section{Método}

O presente trabalho caracterizou-se como estudo descritivo de natureza qualitativa e quantitativa, pois é um tipo de pesquisa de levantamento, que tem como objetivo primordial a descrição das características de determinada população ou fenômeno ${ }^{22}$.

De acordo com ANDRÉ ${ }^{23}$, o estudo qualitativo observa o fato no meio natural, buscando enfatizar a compreensão da singularidade e a contextualidade de fatos e eventos e permite perceber que o componente subjetivo é um aspecto relevante neste tipo de pesquisa. Porém, embora a pesquisa quantitativa seja considerada objetiva, nela também existe o componente subjetivo, pois apesar de todos os controles metodológicos, a pesquisa quantitativa e suas descobertas são inevitavelmente influenciadas pelos interesses e pelas formaçóes social e cultural dos envolvidos. Tais fatores influenciam a formulação de questôes e hipóteses da pesquisa, assim como a interpretação de dados e relaçóes.

\section{Participantes}

Fizeram parte deste estudo 64 professores efetivos, sendo 31 de Educação Física e 33 de Arte do $1^{\circ}$ ao $5^{\circ}$ Ano em 31 escolas (19 estaduais e 12 municipais) do Ensino Fundamental Estadual e Municipal de uma cidade do interior do Estado de Sáo Paulo.

\section{Instrumento}

Para a coleta de dados utilizou-se um questionário, especificamente desenvolvido para esta pesquisa. O questionário continha nove questôes, sendo uma indagação sobre as características gerais dos participantes, sete perguntas abertas e uma fechada com a intenção de examinar as respostas de um grupo de professores sobre as indagaçóes relativas às crenças e práticas educativas a respeito da dança na escola.

\section{Procedimentos}

Este estudo foi aprovado pelo Comitê de Ética da Faculdade de Ciências, tendo sido devidamente aprovado em 22 de novembro de 2012 (Processo 13076/46/01/12), UNESP, Campus Bauru.

$\mathrm{O}$ instrumento de coleta de dados foi entregue para os professores na própria escola, permitindo-se que os mesmos pudessem levá-lo para casa e entregá-lo na semana seguinte. O critério de seleção foi estabelecido basicamente de acordo com o interesse dos participantes. Contudo optamos pelos professores efetivos de cada unidade escolar por acreditar que os professores geralmente permanecem na mesma escola por um período maior e por estarem mais comprometidos com um trabalho diferenciado em relação aos conteúdos das aulas de Educação Física e de Arte, e especificamente neste estudo com os conteúdos de dança na escola.

Para garantir o anonimato dos participantes no decurso deste estudo vamos denominá-los com as siglas das referidas disciplinas: professores de Educação Física Estadual (EFE), Educação Física Municipal (EFM), Arte Estadual (AE) e Arte Municipal (AM) com seus respectivos números de acordo com a ordem da devolutiva dos respondentes.

\section{Análise dos dados}

As respostas foram tabuladas, categorizadas e submetidas a tratamento estatístico descritivo, cuja análise se desenvolve através da descrição dos dados e a avaliaçấo das generalizaçóes obtidas a partir desses achados $^{22}$. Na dimensão qualitativa, de acordo com Chizzotti ${ }^{24}$ os dados coletados foram analisados a partir dos significados que sujeitos e ou pesquisador atribuem ao fato, na qual se fundamenta em uma estratégia baseada em dados coletados em interaçóes sociais ou interpessoais. 


\section{Resultados}

Os dados coletados ${ }^{\mathrm{a}}$ através do questionário forneceram inicialmente informaçôes sobre os aspectos pessoais e o contexto onde estão inseridos os participantes e posteriormente as respostas pertinentes aos conteúdos de dança na escola.

\section{Identificação geral}

Com relação aos dados pessoais, constatou-se que 49 (77\%) professores são do sexo feminino e $15(23 \%)$ do sexo masculino. A média de idade dos participantes foi de 41 anos (mínima de 21 anos e máxima de 60 anos). Quanto ao estado civil dos participantes, 29 (45\%) eram casados, 28 (44\%) eram solteiros, quatro $(6 \%)$ separados, dois $(3 \%)$ eram viúvos e um $(2 \%)$ mencionou manter uma união estável.

Dos 64 professores efetivos de Educação Física e de Arte, 31 (48\%) participantes são professores de Educação Física, sendo 22 (71\%) pertencentes à rede estadual e nove (29\%) a rede municipal de ensino e 33 (52\%) são professores de Arte, sendo $20(61 \%)$ da rede estadual e $13(39 \%)$ da rede municipal.

\section{A dança na ótica dos professores de Arte e de Educação Física}

De acordo com as respostas pertinentes à percepção dos professores de Arte e de Educação Física do ensino da dança na escola emergiram cinco categorias de análise:

- a dança no Projeto Político Pedagógico;

- o ensino dos conteúdos de dança nas aulas de Arte $e$ de Educação Física;

- o conhecimento dos conteúdos de dança preconizado nos PCN's;

- a importância do ensino da dança na escola; $\mathrm{e}$

- os limites do ensino da dança na escola.

\section{A dança no Projeto Político Pedagógico}

Com referência à dança estar contemplada no PPP da escola as respostas foram diversas, por isso agrupamos em categorias apresentadas na FIGURA 1. Os aspectos divergentes se referem às categorias: "Branco"; "Satisfatório"; "Não tem conhecimento" e "Não tem peso maior", sendo que seis (19\%) professores de Arte deixaram em branco e dois (6\%) responderam que os conteúdos de dança náo tem peso maior do que os demais conteúdos desta disciplina. Já para quatro (12\%) professores de Educação Física, os conteúdos de dança são ministrados de maneira satisfatória e dois $(6 \%)$ não têm conhecimento. Nas demais categorias não houve diferença substancial nas respostas dos professores de Educação Física com os professores de Arte.

Na categoria "Currículo" (FIGURA 1), agrupouse as respostas dos participantes referentes às comemoraçōes festivas, proposta curricular, conteúdo de Arte e Educação Física, expressão corporal e PCN's de Arte. Evidenciou-se que 18 (57\%) professores de Arte e 17 (49\%) de Educação Física contemplam os conteúdos de dança no PPP, no qual observamos que náo houve diferença entre as respostas dos professores de Arte e Educaçáo Física.

No que se refere à categoria "Tempo escolar" (FIGURA 1), verificou-se que dois (6\%) professores de Arte e quatro (12\%) de Educação Física destinam poucas horas de atividade ao ensino da dança, como podemos evidenciar nestes discursos: AE8 "Muito pouco, só teoria, pouca prática"; EFM3 "Poucas horas de atividade"; EFE8 "De maneira superficial e minima"; AE1 e EFM6 "Trabalha no $2^{\circ}$ bimestre" e AM12 "no 40 bimestre".

Ao agruparmos as categorias "Branco", "Não faz parte do PPP" e "Não têm conhecimento" (FIGURA 1 ), constatou-se que nove (28\%) participantes de Arte e nove (24\%) de Educação Física não contemplam a dança no PPP. 


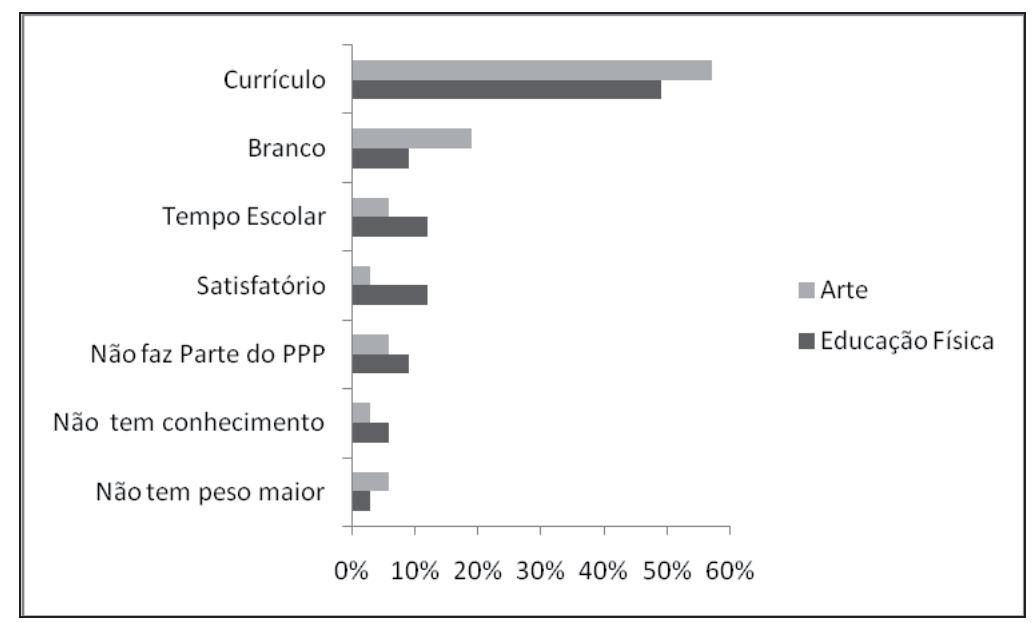

FIGURA 1 - Como a dança está contemplada no Projeto Político Pedagógico da escola segundo os professores de Arte e Educação Física.

Ensino dos conteúdos de dança nas aulas de Arte e de Educação Física

Dentre os momentos nos quais os professores trabalham com os conteúdos de dança em suas aulas, destacamos dois pontos interessantes. $\mathrm{O}$ primeiro diz respeito aos professores que aplicam esses conteúdos somente nas festas escolares ou nas datas comemorativas, evidenciando uma diferença relevante entre os professores de Educação Física (62\%) com os de Arte (16\%).

O segundo ponto é o fato dos professores de Arte $(62 \%)$ mencionarem que trabalham com os conteúdos de dança nos mais diversos momentos, entre eles: quando orientam os alunos a criarem coreografias; em algumas brincadeiras através de jogos teatrais que envolvem "música + dança"; apresentaçóes que envolvem teatro; em leituras de imagem que mostrem alguma manifestação de dança, sempre lembrando aos alunos que os movimentos artísticos não se restringem exclusivamente a pintura e artes visuais; através de manifestaçōes populares; de músicas que envolvem expressóes corporais; em continuidade aos conteúdos propostos pelo plano de ensino; no decorrer do ano, de acordo com o planejamento e de acordo com a nova proposta.

\section{Conhecimento dos conteúdos de dança preconizado nos PCN's}

No tocante ao conhecimento, aplicabilidade e a viabilidade dos conteúdos de dança sugeridos pelos PCN's das respectivas disciplinas, o ponto mais instigante por parte dos professores de Educação Física e de Arte se refere à viabilidade, pois somente sete (23\%) professores de Educação Física e três (9\%) de Arte consideram viáveis os conteúdos de dança. Um dado preocupante é que 29 (88\%) participantes de Arte e 17 (55\%) professores de Educação Física náo comentaram sobre esse aspecto da questão, deixando em branco.

No âmbito mais amplo, nossos achados mostram que tanto os 25 (81\%) professores de Educação Física quanto os 25 (76\%) de Arte conhecem os conteúdos de dança sugeridos pelos PCN's de suas respectivas disciplinas, contudo, 15 (48\%) professores de Educação Física aplicam muito pouco esses conteúdos e 15 (46\%) de Arte relataram aplicar, mas com restrições os conteúdos de dança na escola.

Através de uma pergunta fechada, os professores de Arte e de Educação Física podiam escolher dentre as várias alternativas os conteúdos de dança desenvolvidos durante as suas aulas de acordo com os PCN's de Educação Física (FIGURA 2). 


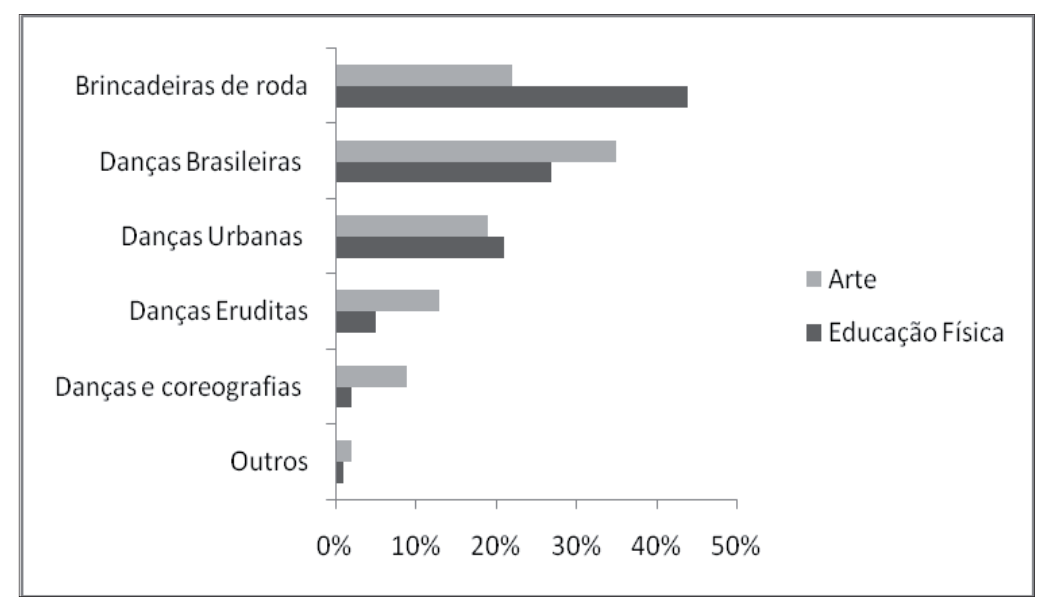

FIGURA 2 - Conteúdos de Dança desenvolvidos nas aulas pelos professores de Arte e de Educação Física de acordo com os PCN’s de Educação Física.

Segundo as respostas sobre os PCN's de Educação Física, 63 (44\%) das escolhas dos professores de Educação Física são referentes aos conteúdos relacionados às brincadeiras de roda como as lengalengas, cirandas e escravos-de-jó, enquanto 76 (35\%) respostas dos professores de Arte dizem respeito aos conteúdos referentes às danças brasileiras, entre os citados estão o samba, baiáo, valsa, quadrilha, bumba-meu-boi, catira, maracatu e xaxado. Já 29 (13\%) indicaçóes dos professores de Arte são referentes às danças eruditas e $29(9 \%)$ citaram as danças e coreografias associadas a manifestaçôes culturais. Dentre as opçóes de escolha, constatou-se que os professores de Educação Física e de Arte deixaram muitas alternativas em branco e no campo "Outros" tivemos poucas indicações, uma vez que eles tinham mais uma possibilidade para mencionar outros conteúdos de dança que não estivessem contemplados na lista de categorias (FIGURA 2).

$\mathrm{Na}$ parte referente aos conteúdos sugeridos pelos PCN's de Arte, das 296 indicaçôes, 134 (45\%) respostas se referem à categoria Dança na expressáo e na comunicação humana; 77 (26\%) indicaçóes para categoria Dança como manifestação coletiva e 85 (29\%) respostas destinavam-se a categoria Dança como produto cultural e apreciação estética.

\section{Importância do ensino da dança na escola}

Com relação à importância do ensino da dança na escola, 64 (100\%) professores de Arte e de Educação Física consideram importante os conteúdos de dança na escola. Como exemplo, destacaremos alguns discursos como relatado por EFM6 "É importante que as crianças tenham o maior número de vivências possíveis, para conhecer ritmos e músicas que talvez não tenham oportunidade de conhecer fora da escola"; EFE17 "É muito importante diversificar as atividades e proporcionar oportunidades de vivência artística aos alunos. A diversificação entre atividade física e expressão artística é muito interessante"; AM3 "Porque é uma forma de expressar sentimentos, emoçóes e principalmente arte, refletindo também as características e gostos de determinadas regiôes e épocas" e AM19 "Como toda a linguagem da arte estimula os alunos, eles conhecem os seus corpos melhor, trabalha a sua sensibilidade".

Observou-se algumas divergências entre as opiniōes dos professores de Arte e de Educação Física a respeito de quem deveria ministrar os conteúdos de dança na escola (FIGURA 3). Para oito (23\%) professores de Educaçấo Física cabe a eles ministrar tais conteúdos enquanto 10 (30\%) de Arte citaram que os três profissionais (Educação Física, Arte e Especialista em Dança) estáo aptos a ministrar tais conteúdos argumentando que a dança se enquadra tanto a Arte como a Educação Física e ambos os professores deveriam ser orientados e acompanhados por um especialista que fornecesse subsídios e recursos para um melhor desenvolvimento dos conteúdos e porque as crianças usam o corpo para se expressar, pois já são naturalmente expressivas. Verificou-se ainda que quatro (12\%) professores de Arte descreveram que caberia a eles ministrar os conteúdos de dança na escola (FIGURA 3). 
Na FIGURA 3 evidenciou-se um ponto comum entre os professores de Educação Física (29\%) e de Arte (30\%), no qual ambos responderam que o ideal seria o especialista em dança como podemos observar nesses relatos de EFE5 "Um especialista em dança porque nós não temos formação suficiente, as disciplinas em dança que fizemos na faculdade são suficientes apenas para aplicar o movimento" e EFE16 "Um especialista em dança, pois o mesmo possui experiência e uma "imagem” maior em relação aos conteúdos e estilos de dança”.

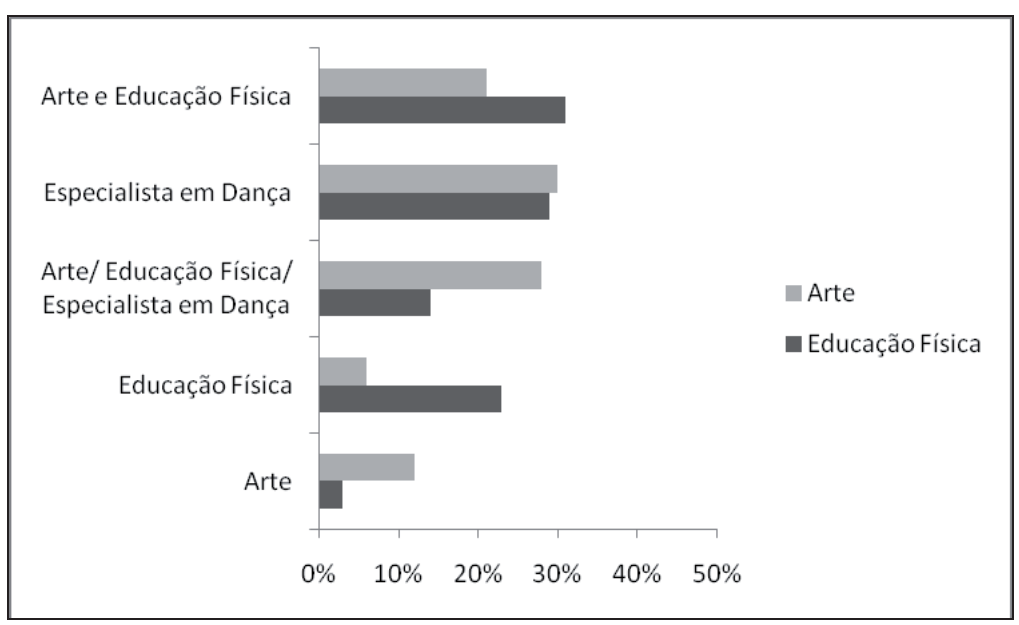

FIGURA 3 - Opinião dos professores de Arte e de Educação Física a respeito de quem deveria ministrar os conteúdos de dança na escola.

\section{Limites do ensino da dança na escola}

As respostas referentes às limitaçóes/dificuldades foram distribuídas em seis categorias. Os aspectos mais divergentes entre os professores de Educação Física e de Arte (FIGURA 4) encontradas no ensino da dança na escola se referem à questão da infraestrutura e material de apoio da escola. Para 27 (43\%) professores de Arte, a falta de espaço físico adequado (de preferência um local fechado, sala ambiente), bem como, materiais pedagógicos, vídeo, livros, ilustraçóes para visualização e aparelho de som prejudicam o desenvolvimento desses conteúdos.

Outro aspecto evidenciado por 13 (28\%) professores de Educação Física (FIGURA 4) diz respeito à timidez apresentada pelos alunos, principalmente pelos meninos, os quais demonstram resistência, desinteresse e preconceito em relação à dança. Nos demais aspectos não houve uma diferença relevante.

Com referência as similaridades nas respostas tanto dos professores de Educação Física quanto de Arte sobre a categoria "Diversos Motivos" destacam-se a falta de cultura dos alunos; o interesse dos alunos por determinados tipos de dança (hip-hop e funk); a padronização erotizante em alguns estilos musicais; pouco tempo para trabalhar os conteúdos de dança; o ensino da dança estar vinculado a outras disciplinas; o receio em atrapalhar as outras salas por causa do barulho, salas numerosas e o alunado heterogêneo (FIGURA 4).

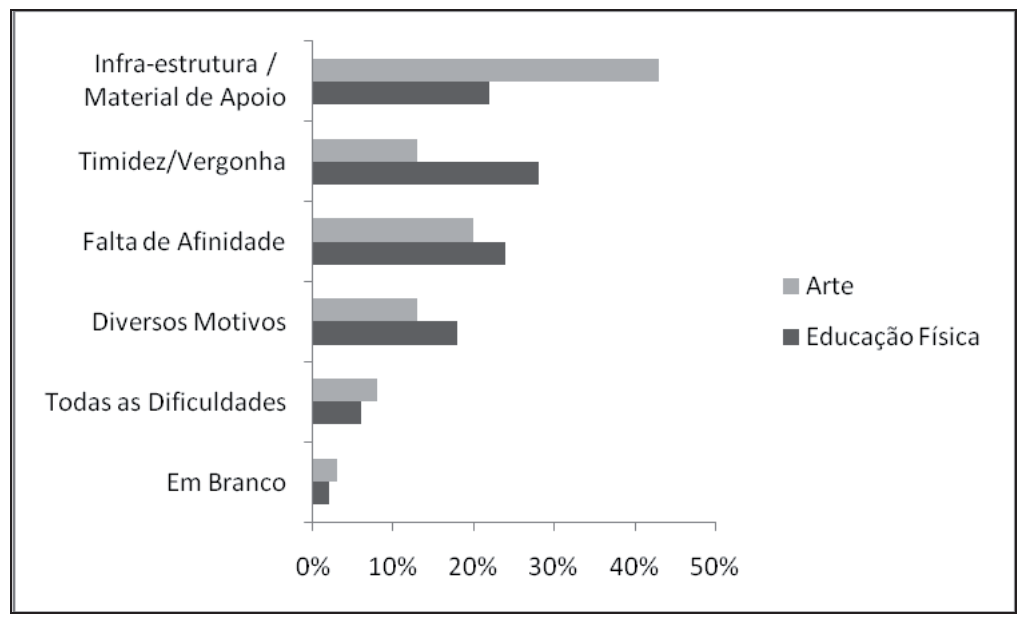

FIGURA 4 - Dificuldades encontradas pelos professores de Arte e de Educação Física no ensino de dança na escola. 


\section{Discussão}

Apresentaremos neste momento as discussōes referentes às cinco categorias de análise emergidas do questionário sobre o ensino da dança na ótica dos professores de Arte e de Educação Física: a dança no Projeto Político Pedagógico; o ensino dos conteúdos de dança nas aulas de Arte e de Educação Física; o conhecimento dos conteúdos de dança preconizado nos PCN'; a importância do ensino da dança na escola $\mathrm{e}$ os limites do ensino da dança na escola.

\section{A dança no Projeto Político Pedagógico}

Através do agrupamento das categorias (FIGURA 1) realizado para apresentar como a dança está inserida no PPP da escola, constatou-se que apesar das divergências encontradas em algumas delas ("Branco"; "Satisfatório"; "Não tem conhecimento" e "Não tem peso maior"), pôde-se inferir que os nossos resultados demonstram que não há uma participação efetiva e coletiva tanto dos professores de Arte (31\%) quanto de Educaçáo Física (30\%) na construção do PPP, se considerarmos que a principal possibilidade dessa construção passa pela relativa autonomia da escola, de sua capacidade de delinear sua própria identidade.

Para VeIgA ${ }^{9}$ isto significa resgatar a escola como espaço público, lugar de debate, do diálogo, fundado na reflexão coletiva. A autora enfatiza também que é preciso entender que o PPP da escola dará indicaçóes necessárias à organizaçáo do trabalho pedagógico, que inclui o trabalho do professor na dinâmica interna da sala de aula. Para que a construção do PPP seja possível, faz-se necessário propiciar situações aos professores, a equipe escolar e os funcionários que lhes permitam aprender a pensar e a realizar o fazer pedagógico de forma coerente?.

Por outro lado, notamos que em torno da metade dos professores de Arte (57\%) e Educação Física (49\%) respondeu que os conteúdos de dança estão contemplados no PPP da escola, como podemos observar na categoria "Currículo", entretanto, não ficou evidenciado como ocorre esse processo de construção do conhecimento, devido as respostas serem muito gerais (comemoraçôes festivas, proposta curricular, expressão corporal, conteúdo de Educação Física e PCN's de Arte) e não demonstrarem claramente como o processo de ensino e aprendizagem está atrelado a uma concepção de educação, que por sua vez, está relacionado às concepçôes de conhecimento e de currículo e que devem constar do PPP da instituição ${ }^{16}$.
De acordo com VEIGA ${ }^{9}$ o currículo refere-se à organização do conhecimento escolar, portanto, faz-se necessário promover na escola uma reflexão aprofundada sobre o processo de produção do conhecimento escolar, uma vez que ele é, ao mesmo tempo, processo e produto. A análise e a compreensão do processo de produçáo do conhecimento escolar ampliam a compreensão sobre as questôes escolares.

Através da categoria "Tempo Escolar" verificou-se que além do ensino da dança ter poucas horas de atividade para $6 \%$ dos professores de Arte e $12 \%$ de Educação Física, ela é trabalhada superficialmente, nas quais a ênfase é a teoria, com pouca prática. Essa estrutura pode comprometer a qualidade do ensino destinado a esses conteúdos.

Por isso, VeIGA ${ }^{9}$ ressalta que a organização do tempo do conhecimento escolar é marcada pela segmentação do dia letivo, e o currículo é organizado em períodos fixos de tempo para disciplinas supostamente separadas. Podemos inferir que esse aspecto é um ponto importante a ser considerado na seleção e organização dos conteúdos a serem desenvolvidos em uma disciplina.

Assim, Vasconcellos ${ }^{16}$ complementa que a previsáo do tempo revela a prioridade dada a cada parte e que se trata sempre de uma estimativa, mas é importante para a viabilização da proposta. Para VeIgA ${ }^{9}$, é preciso tempo para que os educadores aprofundem seu conhecimento sobre os alunos e sobre o que estáo aprendendo para alterar a qualidade do trabalho pedagógico.

Observou-se que uma parcela representativa de professores de Arte (28\%) e de Educação Física (24\%) não contempla a dança no PPP, o que pode comprometer a inclusão deste conteúdo nas respectivas disciplinas.

São preocupantes esses resultados porque quase $30 \%$ desses educadores não quiseram opinar (quando deixaram em branco a questáo), além de mencionar que os conteúdos de dança não estão contemplados no PPP e não tem conhecimento. Podemos inferir que este conteúdo não esteja sendo discutido e inserido no cotidiano escolar. SCARPATO ${ }^{14}$ ressalta que a carência na aplicabilidade desse conteúdo nas aulas de Educação Física e acrescentamos também nas aulas de Arte, podem acarretar dúvidas em como trabalhar a dança no espaço escolar.

Diante desta constatação, GADOTTI ${ }^{25}$ ressalta que na construção do PPP os pressupostos e instrumentais teórico-metodológicos da escola geram-se 
no coletivo escolar, pelo processo de discussão, que cada escola for capaz de implementar no seu ritmo e tempos próprios e na dimensão das vontades dos coletivos nela atuantes.

Construir o projeto pedagógico de uma escola é mantê-la em constante estado de reflexão e elaboração numa esclarecida recorrência às questôes relevantes de interesse comum e, historicamente, requeridos, bem como na busca de alternativas viáveis à efetivação de sua intencionalidade e assenta-se numa dimensão de globalidade e totalidade da educação?

\section{Ensino dos conteúdos de dança nas aulas de Arte e de Educação Física}

Ao indagarmos os professores de Arte e de Educaçáo Física sobre os momentos nos quais trabalham com os conteúdos de dança, observou-se que para a maioria dos professores de Educaçáo Física (62\%), a dança ainda é vista como sinônimo de festividade ${ }^{2}$.

Esses dados retratam a situação em que se encontram os conteúdos de dança e confirmam pesquisas realizadas por SCARPATO ${ }^{14}$, Rocha e Rodrigues ${ }^{26}$, Sousa et al. ${ }^{27}$ e Finck e CAPRI ${ }^{28}$, na qual a dança no contexto escolar vem sendo trabalhada somente em festas escolares, principalmente nas festas juninas, das mães, dos pais e em eventos especiais de acordo com o cronograma da unidade escolar.

Essa constatação de que o ensino da dança só é lembrado diante da necessidade de se mostrar espetáculos para serem apresentados à comunidade foi evidenciada por vários pesquisadores ${ }^{2,14,19,29-34}$ desde década de 90.

Nesta mesma direção, Brasileiro ${ }^{34}$ enfatiza que hoje é cada dia mais evidente a presença da dança nas escolas, porém ainda marcadamente nos espaços festivos e apesar de ser caracterizada, nos documentos curriculares, como um conteúdo da arte e da educaçáo física, ou seja, conhecimento a ser ensinada no espaço de formação de crianças e adolescentes, a mesma aparece e desaparece em programas escolares, ou seja, a dança presente nas festas é quase sempre ausente dos componentes curriculares.

Podemos inferir que nossos resultados refletem em parte (em torno de 62\% desse grupo de professores) a situação da desvalorização que se encontra a dança no ambiente escolar, por utilizá-la somente em eventos pontuais. Nas palavras de SBorquia e GalHardo ${ }^{35}$ a dança é descontextualizada da cultura e, consequentemente marginalizada no currículo escolar, sendo apenas realizada mediante eventos extracurriculares, em que a grande maioria das escolas degrada a Cultura Popular Brasileira ao organizar simulacros de "festas juninas".

No que tange ao segundo aspecto, os professores de Arte (62\%) revelaram que trabalham com os conteúdos de dança nos mais diversos momentos em suas aulas. Através desses relatos podemos inferir que um número maior de docentes está tentando ministrar tais conteúdos, entretanto, relatam de uma maneira geral, em que náo especificam quanto tempo (se é esporádico ou bimestral, o número de aulas) é destinado a esses conteúdos nem como ocorre o processo de ensino e aprendizagem. Apesar de não encontrarmos na literatura resultados semelhantes, esses achados mostram um caminho para que seja possível o ensino de dança na escola.

\section{Conhecimento dos conteúdos de dança preconizado nos PCN's}

$\mathrm{Na}$ indagação referente ao conhecimento, aplicabilidade e a viabilidade dos conteúdos de dança sugeridos pelos PCN's das respectivas disciplinas, mais da metade dos professores de Educação Física $(55 \%)$ e Arte (88\%) não responderam, deixando em branco, o que podemos inferir que eles não querem se posicionar sobre o assunto. Constatou-se ainda que tanto os professores de Educação Física (81\%) quanto os de Arte (76\%) conhecem os conteúdos de dança sugeridos pelos PCN's de suas respectivas disciplinas, entretanto, a aplicação desses conteúdos pelos docentes de Educaçáo Física (48\%) e de Arte (46\%) é muito restrita.

Podemos relacionar nossos resultados com o trabalho realizado por Peres et al. ${ }^{36}$. Nesta pesquisa, $84,2 \%$ dos professores conhecem os aspectos sobre a inclusão da dança na Educação Física de acordo com o Currículo Básico para a Escola Pública do Estado do Paraná. Este documento preconiza o corpo em movimento como objeto de estudo da Educaçáo Física, no qual estão incluídos a ginástica, a dança, os jogos e os esportes como principais conteúdos, procurando desempenhar um papel verdadeiramente educativo o que corresponde com os PCN's de Educação Física.

Diante das respostas a respeito da indagação fechada sobre a seleçáo dos conteúdos de dança sugeridos pelos PCN's de Arte e de Educação Física, constatou-se que houve uma divergência das informaçôes obtidas através de uma questão aberta parecida sobre como você trabalha com os conteúdos de dança nas suas aulas, evidenciando que uma grande parcela dos professores $(61 \%$ de Educação Física e $76 \%$ de Arte) não trabalham ou trabalham 
muito pouco com esses conteúdos em suas aulas. Percebe-se uma falta de clareza nas respostas, no qual náo permite vislumbrar como os professores ministravam os conteúdos de dança em suas aulas.

Contudo, nessa indagação fechada tem-se a impressão que tanto os professores de Educação Física quanto de Arte desenvolvem os conteúdos de dança sugeridos nos PCN's, nos quais parece estar ocorrendo a valorizaçáo e aplicação da dança na escola, contudo, na realidade escolar verifica-se que essa aplicação é contraditória, uma vez que os professores nesta pergunta tinham as informaçóes sobre os conteúdos de dança dos PCN's, mas é provável que realmente náo estivessem ministrando todos esses conteúdos elencados nesta questáo.

$\mathrm{Na}$ visão de Rocha e Rodrigues ${ }^{26}$, as inovaçôes e intençóes educacionais nem sempre são perceptíveis. Quando não há uma preparação adequada, resulta em certa dificuldade em entender como os PCN's se concretizam no agir do profissional. Percebe-se que esse discurso náo chega à escola. É importante que o profissional tenha consciência que os PCN's são um documento que necessita de reflexão e atualização, e um profissional desatualizado que apresenta uma formação profissional insuficiente e com certas deficiências terá sua prática pedagógica comprometida. Sem uma prática pedagógica dimensionada, não podemos abordar com maiores possibilidades os conteúdos da Educação Física Escolar.

Nessa perspectiva, SILVA ${ }^{37}$ ressalta que embora a dança seja citada nos PCN's como conteúdo das disciplinas de Educação Física e Arte, parece que nenhuma das duas disciplinas tem dado conta de trabalhar a dança de forma sistematizada e contínua, pois é abordada esporadicamente.

\section{Importância do ensino da dança na escola}

Os professores de Educação Física e de Arte desse estudo consideraram importante os conteúdos de dança na escola. Corroborando com nossos resultados, Peres et al. ${ }^{36}$ aplicaram um questionário com nove questóes fechadas e semiabertas para 19 professores de Educação Física das escolas estaduais de Maringá. Os resultados dessa pesquisa demonstram que embora os professores considerem importante conhecer os conteúdos abordados na dança escolar, percebe-se que a falta desses conhecimentos é a principal dificuldade dos docentes, acreditando-se ser preciso buscá-los. Para isso, é preciso lutar contra as dificuldades relacionadas às condiçóes materiais da escola e contra ao preconceito das pessoas e suas próprias restriçóes, a fim de tornar possível a sua inclusão como conteúdo escolar.

No que tange a opiniáo dos professores de Educaçáo Física e de Arte a respeito de quem deveria ministrar os conteúdos de dança na escola, podemos inferir que tanto professores de Educação Física quanto de Arte apontaram aos profissionais de cada disciplina a responsabilidade de ministrar tal conteúdo, evidenciando uma maneira de defender e preservar esse direito a sua área de atuação.

Os professores de Educação Física consideram-se aptos argumentando que receberam orientação sobre o assunto na graduação e podem estabelecer uma interdisciplinaridade uma vez que ele é o professor da turma. Já os professores de Arte acreditam que podem ministrar os conteúdos de dança, desde que tivessem uma formação que possibilitasse desenvolver um trabalho mais eficiente e que dominasse $\mathrm{o}$ assunto.

Os professores de Educação Física e de Arte ressaltaram que um especialista em dança seria o profissional mais indicado para ministrar os conteúdos de dança na escola. Podemos inferir que essas respostas podem estar associadas com a formação inicial, pois segundo Barreto $^{13}$ e Pereira ${ }^{1}$ as graduaçóes dessas duas áreas não estão conseguindo dar subsídios suficientes para que esses professores se sintam aptos para aplicar esses conteúdos em suas aulas.

\section{Limites do ensino da dança na escola}

As divergências encontradas sobre as limitações/ dificuldades dos professores de Arte e Educação Física no ensino da dança na escola se referem à questão da infraestrutura, material de apoio da escola, à timidez do gênero masculino ${ }^{38}$, desinteresse ${ }^{28}$, preconceito $^{19}$, a falta de espaço físico adequado, de sala ambiente, materiais pedagógicos ${ }^{39} \mathrm{e}$ aparelho de som.

No que se refere à categoria denominada "Diversos Motivos" encontramos similaridades nas respostas tanto dos professores de Educação Física quanto de Arte sobre a ausência de cultura dos alunos, interesse por estilos de dança específicos, a padronização erotizante, pouco tempo destinado para os conteúdos de dança, o vínculo do ensino de dança com outras disciplinas, salas numerosas e heterogêneas, receio em atrapalhar as outras salas devido ao barulho. Os nossos resultados divergem da pesquisa de Peres et al. ${ }^{36}$, em que a maioria dos professores de Educação Física $(84,2 \%)$ dessa pesquisa não possui dificuldade para trabalhar com a dança na escola, pois, apenas $15,8 \%$ disseram apresentar tal dificuldade. Contudo, 
encontramos similaridades em duas dificuldades citadas pelos professores no ensino da dança escolar que foram à falta de instalaçóes e materiais adequados na escola e pouca afinidade com essa atividade.

Comparando nossos dados com o estudo de Silva et al. ${ }^{40}$ com professores de Educação Física da rede estadual de ensino fundamental na cidade de Porteirinha/MG, observou-se que as dificuldades encontradas para ministrar as aulas de dança na Educação Física se diferenciam das nossas categorias, mas que o professor deve contornar essas questóes buscando animar os alunos, colocando de lado o preconceito, inserindo e incentivando, pois é aí que está o papel do professor, resgatar seu aluno e ajudá-lo a se expressar, superando suas dificuldades.

$\mathrm{Na}$ dança são determinantes as possibilidades expressivas de cada aluno, o que exige habilidades corporais que, necessariamente, se obtêm com o treinamento. Em certo sentido, esse é o aspecto mais complexo do ensino da dança na escola. A decisáo de ensinar gestos e movimentos técnicos prejudicando a expressão espontânea, ou de imprimir no aluno um determinado pensamento/ sentido/ intuitivo da dança para favorecer o surgimento da expressão espontânea, abandonando a formação técnica necessária à expressão certa ${ }^{40}$.

MorANDi $^{2}$ enfatiza que a arte do movimento faz parte da educação quando se compreende que a dança é a arte básica do ser humano e MARQues ${ }^{41}$ ressalta que a construção do conhecimento em dança envolve uma apropriação reflexiva, consciente e transformadora do movimento.

Dessa maneira, definiu-se como objetivo desta pesquisa investigar o ensino da dança na escola. Através dos relatos dos professores de Arte e Educação Física foi possível refletir sobre como os conteúdos de dança estão contemplados no PPP da escola, como ocorre esse ensino nas aulas de Arte e Educação Física, bem como, o conhecimento que esse grupo de professores possuem em relação aos conteúdos de dança preconizado nos PCN's; a sua importância e ainda, as dificuldades enfrentadas pelos educadores para ministrar tais conteúdos na escola.

Com os resultados deste estudo evidenciou-se que o ensino da dança na escola carece de um trabalho conjunto dos professores de Arte e Educação Física para que esses conteúdos possam ser contemplados no PPP, pois pôde-se verificar que esse grupo não tem uma participação efetiva e coletiva durante o processo de construção do projeto educacional da escola.

Cabe ressaltar que através da elaboração do PPP os professores terão condiçóes de conhecer a realidade onde ele está trabalhando (nível social, cultural, entre outros conhecimentos) e conversar com os pares sobre os conteúdos (no nosso caso específico, a dança) a serem abordados durante o ano e dessa maneira, promover a interdisciplinaridade entre as disciplinas, proporcionando um conhecimento integral para os alunos.

Neste sentido, concordamos com VeIGA ${ }^{9}$ ao enfatizar que o PPP é um exercício de construção permanente que acompanha e é acompanhado pela prática pedagógica, cotidianamente se fazendo e refazendo. Complementando, LibÂNEO ${ }^{42}$ destaca que o PPP constitui-se num processo democrático de decisóes, não apenas de um mero documento, mas da execução coletiva deste processo de ação e de reflexão. Ele instaura formas de organização escolar pedagógica e diminui a fragmentação do trabalho em sua globalidade, alcançando assim, uma gestão participativa.

Quanto ao ensino da dança na escola, constatou-se que a maioria dos docentes de Educação Física não está ministrando os conteúdos de dança priorizando o processo educacional, pois tais conteúdos continuam relegados às festividades escolares, na qual se apresenta sem sentido, sem contextualização histórica, social, cultural, enfim, sem um objetivo voltado para o ensino e aprendizagem. Um dado interessante desta categoria se refere aos professores de Arte que relataram trabalhar com os conteúdos de dança em diversos momentos, o que pode demonstrar um novo olhar sobre a compreensão da importância da dança na educação.

Outra constatação foi que os professores de Arte e Educação Física conhecem os conteúdos de dança sugeridos pelos PCN's das respectivas disciplinas, entretanto, aplicam muito pouco e com algumas restrições esses conteúdos em suas aulas. Por isso, concordamos com Peres et al. ${ }^{36}$ quando ressaltam que somente ter o conhecimento dessa inclusão não é o suficiente; é preciso colocá-la em prática, para que se desenvolva o papel educacional da dança. Esse fator é, muitas vezes, desconsiderado pelos professores e pela própria direção da escola.

Diante do exposto, um possível caminho para amenizar essa problemática poderia ser alcançado através do estudo dos PCN's de Arte e Educação Física, no qual os professores se debruçariam sobre esse material para discutir, refletir, selecionar e organizar os conteúdos de dança compatíveis com as possibilidades de aprendizagem dos alunos, respeitando as especificidades de cada área, contribuindo dessa maneira para a construção de um trabalho educacional integrado voltado para o ensino da dança na escola.

Os professores de Arte e Educação Física desta pesquisa consideraram importantes os conteúdos 
de dança, contudo, só o reconhecimento não é suficiente para garantí-los na escola. Percebeu-se ainda que esse grupo de docentes tentaram preservar a sua área de atuação quando questionados sobre quem deveria ministrar a dança na escola, entretanto, tanto os educadores de Arte quanto de Educação Física mencionaram que o especialista em dança estaria melhor preparado para ministrar tais conteúdos. Cabe questionar se esse especialista utilizaria os conteúdos de dança voltados para os aspectos educacionais preconizados na escola ou somente para o tecnicismo acadêmico de determinado estilo de dança.

No que tange os limites do ensino da dança na escola, uma das dificuldades apresentadas pelos professores de Arte se refere à infraestrutura e o material didático de apoio. Diante dessas constataçôes, observou-se que a maioria das escolas náo oferece um espaço amplo e adequado para a realização das aulas de dança, bem como, material pedagógico na escola para subsidiar a prática pedagógica docente. Essas dificuldades demonstram que é preciso proporcionar momentos de discussóes e reflexóes acerca destas questóes na escola por toda equipe escolar, procurando encontrar soluçóes para amenizar esses problemas através da reestruturação da organização da estrutura física, bem como, na aquisição e compartilhamento dos materiais didáticos para que assim seja possível realizar um ensino significativo de dança na escola.

Corroborando com nossos apontamentos, SiLva et al. ${ }^{40}$ destacam que a dança entendida como linguagem artística, tão necessária ao desenvolvimento do ser humano, parece ser uma atividade que ainda está nascendo nas escolas, e como tal, necessita de investigação e reflexão constante para tornar-se efetiva em seu âmbito escolar.

Dessa maneira, ressalta-se, ainda a importância da união dos professores de Arte e de Educação Física para a realização dos estudos, análises, discussóes e reflexões a respeito do ensino da dança, na tentativa de verificar como cada especialista pode auxiliar e contribuir para que a dança seja efetivamente ministrado no contexto escolar, promovendo assim a interdisciplinaridade dessas áreas, contudo, conhecendo e respeitando as singularidades e competências de cada uma².

Conclui-se como necessária à união e integração desses educadores em prol do ensino da dança na escola, para que ela ocupe efetivamente seu espaço nas aulas de Arte e Educação Física. Essa integraçáo pode ser o início do processo de elaboração de projetos educacionais com objetivo comum, com o intuito de estimular e motivar os alunos a participarem de um trabalho educativo voltado para os conteúdos de dança na escola.

\section{Notas}

a. Algumas dificuldades foram encontradas durante a coleta de dados. O primeiro impasse foi agendar um horário compatível com os coordenadores e professores para a explicação da pesquisa. Em seguida a devolutiva do instrumento, precisando-se retornar várias vezes na mesma unidade escolar. Outro ponto importante a ser destacado é que alguns participantes ministravam aulas em várias unidades escolares, por isso o número de participantes náo corresponde ao total de escolas existentes em Bauru. Além disso, vários professores não quiseram responder, dentre as justificativas apresentadas destacamos que alguns não queriam se posicionar sobre o assunto, outros não trabalham com o conteúdo de dança na escola, outros porque estavam ministrando aulas em várias escolas e não estavam com tempo disponível para responder o questionário.

A autora Nilza Coqueiro Pires de Sousa é bolsista FAPESP e a autora Dagmar Aparecida Cynthia França Hunger é bolsista produtividade CNPq-PQ2. 


\section{Abstract}

Dance teaching at school in optical teachers of Physical Education and Art

The aim of this descriptive study, qualitative and quantitative in nature, was to analyze whether the content is broken down on the dance Political Pedagogical Project (PPP) in the Schools; presents itself as teaching dance classes in Physical Education and Art, which the teachers' knowledge of content in dance recommended National Curriculum, where importance is given to teaching dance at school and what are its limits. It was used a questionnaire with open and closed issues for sixty-four effective teachers of art and physical education of the public State and municipal network of a city in the State of São Paulo in Brazil. In summary, it was found that these teachers do not have an effective and collective participation during the process of construction of the PPP education; they know, but apply very little and with restrictions on the contents of dance suggested by PCN's of their respective disciplines, are basically relegated to the festivities school and dance are the difficulties faced by many teachers in the school dance. We conclude as necessary to unite and integrate these educators in favor of contents school dance, so she effectively occupy its space in Physical Education classes and Art.

KEY WORDS: Dance; Pedagogical political project; National curriculum; Physical education; Arts.

\section{Referências}

1. Pereira ML. A formação acadêmica do professor de educação física: em questão o conteúdo da dança [dissertação]. Rio Claro (SP): Universidade Estadual Paulista, Instituto de Biociências; 2007.

2. Morandi CSD. A dança e a educaçáo do cidadáo sensível. In: Morandi CSD, Strazzacappa M. Entre a arte e a docência: formação do artista da dança. Campinas: Papirus; 2006. p.71-125.

3. Brasil. Ministério da Educação e Cultura. Secretaria de Educação Fundamental. Parâmetros curriculares nacionais: introdução. Brasília: MEC/SEF; 1997.

4. Sáo Paulo (Estado). Secretaria da Educação. Expectativas de aprendizagens de arte $1^{\circ}, 2^{\circ}$ e $3^{\circ}$ anos do ensino fundamental (versão preliminar). São Paulo: Secretaria da Educação; 2012. [citado 8 fev. 2014]. Disponível em: http://www. rededosaber.sp.gov.br/portais/Default.aspx?tabid=2741.

5. São Paulo (Estado). Secretaria da Educação. Roteiro de sugestão de atividades para as aulas de arte e educação física para o início do ano letivo de 2013. São Paulo: Secretaria da Educação; 2013. [citado 8 fev. 2014]. Disponível em: http://lereescrever.fde.sp.gov.br/SysPublic/InternaMaterial.aspx?alkfjlklkjaslkA=266\&manudjsns=0\&tpMat=6\&Filtr oDeNoticias $=3$.

6. Bauru (Município). Secretaria da Educação. Currículo comum para o ensino fundamental municipal de Bauru. Bauru: Secretaria da Educação; 2012. [citado 10 fev. 2014]. Disponível em: http://www.bauru.sp.gov.br/arquivos/arquivos_site/ sec_educacao/dpppe/curriculo.pdf.

7. Brasil. Ministério da Educação e Cultura. Secretaria de Educação Fundamental. Parâmetros curriculares nacionais: arte. Brasília: MEC/SEF; 1997.

8. Brasil. Ministério da Educação e Cultura. Secretaria de Educação Fundamental. Parâmetros curriculares nacionais: educação física. Brasília: MEC/SEF; 1997.

9. Veiga IPA. Projeto político-pedagógico da escola: uma construção coletiva. In: Veiga IPA, organizadora. Projeto políticopedagógico: uma construção possível. Campinas: Papirus; 2011.

10. Ossona P. Educação pela dança. São Paulo: Summus; 1988.

11. Pacheco AJP. A dança na educação física: uma revisão da literatura. Rev Bras Ci Esporte. 1999;21:117-24.

12. Zotovici SA. Dança-educação: uma experiência vivida. Conexóes. 1999;3:119-28.

13. Barreto D. Dança... Ensino, sentidos e possibilidades na escola. São Paulo: Autores Associados; 2004.

14. Scarpato MT. A formação do professor de educação física e suas experiências com a dança. In: Moreira EC, organizador. Educação física escolar: desafios e propostas. Jundiaí: Fontoura; 2004.

15. Betini GA. A construção do projeto político-pedagógico da escola. Educ. 2005;1:37-44. 
16. Vasconcellos CS. Planejamento: projeto de ensino-aprendizagem e projeto político-pedagógico: elementos metodológicos para elaboração e realização. São Paulo: Libertad; 2002.

17. Pellegrini AM. A formação profissional em educação física. In: Passos SCE, organizadora. Educação física e esportes na universidade. Brasília: Ministério da Educação, Secretaria de Educação Física e Desportos; 1988.

18. Braun LG, Saraiva MC. Dança e educaçáo física: uma visão de acadêmicos do curso de educação física da UFSC. VII Congresso Brasileiro de História da Educação Física, Esporte, Lazer e Dança; 2000; Gramado, BR. Gramado: UFRGS; 2000. p.557-62.

19. Gaspari TC. Educação física escolar e dança: uma proposta de intervenção [dissertação]. Rio Claro (SP): Universidade Estadual Paulista, Instituto de Biociências; 2005.

20. Laban R. Domínio do movimento. São Paulo: Summus; 1978.

21. Laban R. Dança educativa moderna. São Paulo: Ícone; 1990.

22. Gil AC. Métodos e técnicas de pesquisa social. São Paulo: Atlas; 2002.

23. André MEDA. Etnografia da prática escolar. Campinas: Papirus; 1995.

24. Chizzotti A. Pesquisa em ciências humanas e sociais. São Paulo: Cortez; 1998.

25. Gadotti M. Projeto político-pedagógico da escola na perspectiva de uma educação para a cidadania perspectivas atuais da educação. Porto Alegre: Artes Médicas; 2001.

26. Rocha D, Rodrigues GM. A dança na escola. Rev Mackenzie Educ Fís Esporte. 2007;6:15-21.

27. Sousa NCP, Hunger DACF, Caramaschi S. A dança na escola: um sério problema a ser resolvido. Motriz. 2010;16:496-505.

28. Finck SCM, Capri, FS. As representaçôes sociais da dança em aulas de educação física nos anos iniciais do ensino fundamental. Práxis Educ. 2011;6:249-63.

29. Fusari MF, Ferraz MH. Arte na educação escolar. São Paulo: Cortez; 1993.

30. Marques IA. Dançando na escola. Motriz. 1997;3:20-8.

31. Verderi EBLP. Dança na escola. Rio de Janeiro: Sprint; 2000.

32. Ehrenberg MC. A dança como conhecimento a ser tratado pela educação física escolar: aproximaçóes entre formação e atuação profissional [dissertação]. Campinas (SP): Universidade Estadual de Campinas, Faculdade de Educação Física; 2003.

33. Souza MJ. A dança na formação do profissional de educaçáo física: legitimaçáo de uma cultura ou quebra de paradigmas? VI Encontro de Pesquisa em Educação da Regiáo Centro- Oeste; 2003; Campo Grande, BR. Campo Grande: Universidade Católica Dom Bosco, Universidade Federal de Mato Grosso do Sul; 2003.

34. Brasileiro LT. O ensino da dança na educação física: formação e intervenção pedagógica em discussão. Motriz. 2008;14:4:519-28.

35. Sborquia SP, Gallardo JSP. As danças na mídia e as danças na escola. Rev Bras Ci Esporte. 2002;23:105-18.

36. Peres AT, Ribeiro DMDB, Martins Junior J. A dança escolar de $1^{\mathrm{a}}$ a $4^{\mathrm{a}}$ série na visão dos professores de educação física das escolas estaduais de Maringá. Revista da Educação Física/UEM. 2001;12:19-26.

37. Silva CKO. A dança em cena: reflexôes sobre a prática de dança no contexto escolar. Cad Pedag. 2011;8:51-60.

38. Sousa NCP, Caramaschi S. Contato corporal entre adolescentes através da dança de salão na escola. Motriz. 2011;17:618-29.

39. Sardelich ME. Formação inicial e permanente do professor de arte na educaçáo básica. Cad Pesq. 2001;114:137-52.

40. Silva WF, Alves DS, Ribeiro GFF. A dança nas escolas da rede estadual de ensino fundamental na cidade de Porteirinha/ MG: análise da sua aplicabilidade e metodologias. Educ Fís Rev. 2010;4. Disponível em: http://portalrevistas.ucb.br/ index.php/efr/article/view/1662/1167.

41. Marques IA. Ensino da dança hoje: textos e contextos. São Paulo: Cortez; 1999.

42. Libâneo JC. Organização e gestão da escola: teoria e prática. Goiânia: Alternativa; 2004.

ENDEREÇO

Nilza Coqueiro Pires Sousa

R. Capitão Alcides, 20-17 Bloco A - apto. 32 15030-510 - Bauru - SP - BRASIL e-mail: nilzacpsousa@yahoo.com.br
Recebido para publicação: 05/09/2012

Revisado: 18/02/2014

Aceito: 10/06/2014 